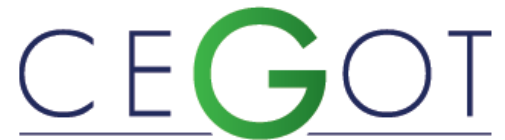

Centro de Estudos de Geografia e Ordenamento do Território
Geografia e Ordenamento do Território, Revista Eletrónica Centro de Estudos de Geografia e Ordenamento do Território http://cegot.org

SANTOS, JOUBERTE

IFPE- Cabo de Santo Agostinho

Sebastião Joventino, S/N, Central Predio Provisório (Fachuca) - Destilaria,

Cabo de Santo Agostinho - PE, Brasil. CEP: 54510-110

jouberte.santos@ifpe.cabo.edu.br

MELLO, SÉRGIO

CCSA - Centro de Ciências Sociais Aplicadas - Universidade

Federal de Pernambuco

Av. Prof. Moraes Rego, 1235 - Cidade Universitária, Recife - PE, Brasil. CEP: 50670-901

Sergio.benicio@gmail.com

\title{
Um olhar arqueológico dos discursos em torno dos Grandes Projetos Urbanos (GPUs): o caso do Projeto Novo Recife
}

An archaeological view of the discourses around the Large Urban Projects (GPUs): the case of the New Recife Project

Referência: Santos, Jouberte; Mello, Sérgio (2018). Um olhar arqueológico dos discursos em torno dos Grandes Projetos Urbanos (GPUs): o caso do Projeto Novo Recife. Revista de Geografia e Ordenamento do Território (GOT), n. ${ }^{\circ} 13$ (junho). Centro de Estudos de Geografia e Ordenamento do Território, p. 409-434, dx.doi.org/10.17127/got/2018.13.018

\section{RESUMO}

O presente trabalho teve como objetivo analisar o discurso do projeto urbanístico "Novo Recife" pelas perspectivas da Prefeitura do Recife e do Consórcio responsável pela obra. Utilizando o método arqueológico de Foucault (2008) encontramos um discurso regulado pela ideia de crescimento econômico como condição de possibilidade de uma cidade mais sustentável. Nossos achados apontaram para a presença do discurso do planejamento estratégico na administração pública do Recife, bem como a utilização dos Grandes Projetos Urbanos (GPUs) como ferramentas adequadas para a construção de uma cidade mais sustentável e para o crescimento econômico. O conjunto de significados inter-relacionados identificados nos remeteram ao estabelecimento de uma grande formação discursiva denominada de "Crescimento Econômico gera sustentabilidade".

Palavras-Chave: GPUS, Crescimento Econômico, Gestão Pública, Arqueologia Foucaultiana

\section{ABSTRACT}

The present work had as objective to analyze the discourse of the urban project "New Recife" from the perspectives of the City Hall of Recife and the Consortium responsible for the work. Using the archaeological method of Foucault (2008) we find a discourse regulated by the idea of economic growth as a condition for the possibility of a more sustainable city. Our findings pointed to the presence of the strategic planning discourse in the public administration of Recife, as well as the use of the Large Urban Projects (LUPs) as appropriate tools for the construction of a more sustainable city and for economic growth. The set of interrelated meanings identified led us to establish a great discourse formation called "Economic Growth generates sustainability". 
Keywords: LUPs, Economic Growth, Public Management, Foucauldian Archeology

\section{Introdução}

O "Novo Recife" é fruto do consórcio estabelecido entre a Prefeitura Municipal de Recife e as construtoras Moura Dubeux, Queiroz Galvão, Ara Empreendimentos e GL empreendimentos. O projeto pretende revitalizar a região central, considerada isolada das demais regiões da cidade.

Segundo a Secretaria de Controle, Desenvolvimento Urbano e Obras da Prefeitura da Cidade do Recife (SECON), o projeto Novo Recife está de acordo com o PRO (Projeto Recife-Olinda, 2003), proposta urbanística que prevê intervenções em faixa litorânea entre os centros históricos da cidades do Recife e Olinda, importantes centros urbanos da região nordeste do Brasil. O Novo Recife abrange as áreas dos Bairros de São José, Cabanga e os eixos viários Avenida Sul e Rua Imperial da Cidade do Recife. Uma área de 101,7 mil metros quadrados onde fica localizado o Cais José Estelita (Prefeitura do Recife, 2015).

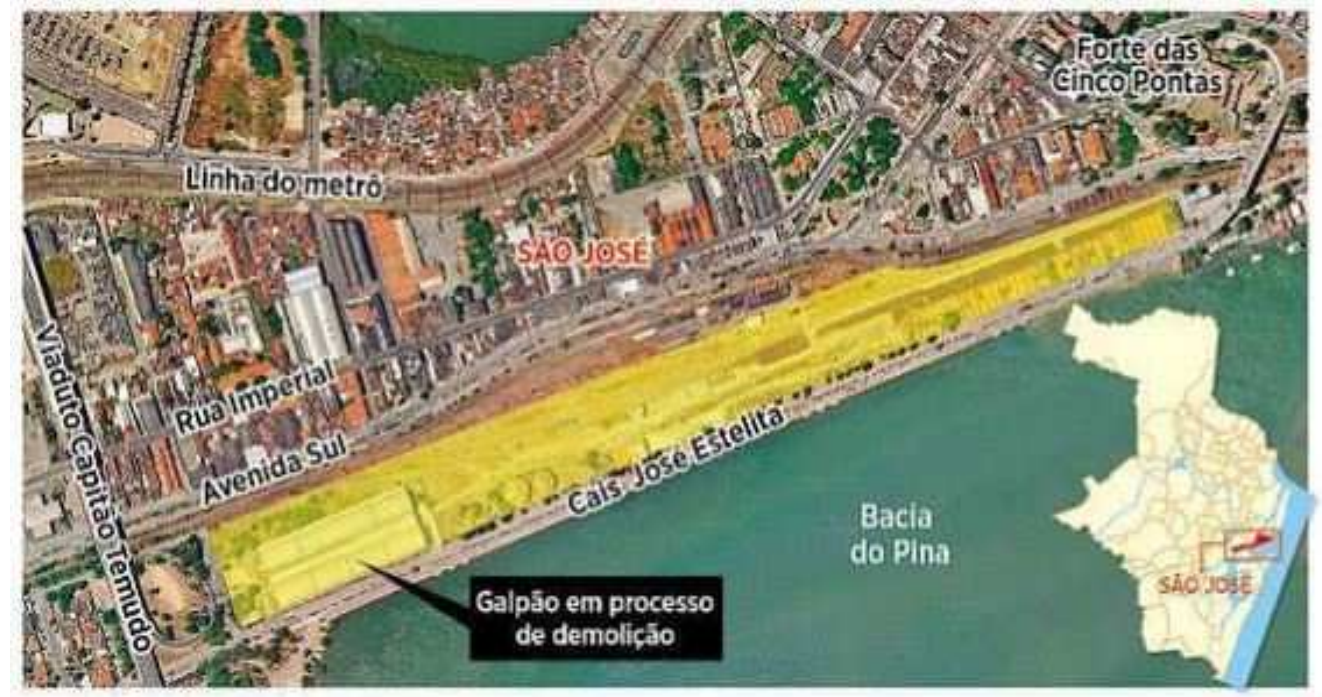

Figura 1 - Localização do empreendimento Novo Recife Fonte: Prefeitura do Recife (2015)

O terreno pertencia à antiga Rede Ferroviária Federal (RFFSA), segunda mais antiga do país, quando foi leiloado, em 2008, com uma única proposta de compra, o Consórcio Novo Recife, pelo valor mínimo de 55 milhões de reais, aproximadamente 540 reais por metro 
quadrado (Truffi, 2014). Por ser um cartão postal da cidade e situar o Porto do Recife, de frente à bacia do Pina, tornou-se uma região que apresenta funções importantes de caráter econômico, social e ambiental para a cidade do Recife (MARCONDES, 2009, p. 13).

De acordo com o Conselho de Desenvolvimento Urbano (CDU), o projeto pretende construir 13 prédios que poderão ter até o tamanho máximo de 44 pavimentos. Serão duas torres comerciais, sete torres residenciais de luxo, dois flats e um hotel. Inclui ainda estacionamentos para 5000 veículos. Como ações para reduzir os impactos negativos, o consórcio também deverá construir quadras poliesportivas, biblioteca pública, mercado popular, ciclovias e parques (PREFEITURA DO RECIFE, 2015).

Grandes empreendimentos como o Novo Recife são de interesse da administração municipal por diversos motivos. Supostamente afetam consideravelmente a arrecadação de impostos, atraem investimentos de grupos econômicos e geram renda e emprego, movimentando a economia local (Oliveira e Barreira, 2011). Em tempos de crise, de cortes no orçamento e queda na arrecadação que vivem a maioria dos municípios brasileiros, nunca foi tão importante viabilizar o aumento na arrecadação e a parceria público-privado como agora.

Atualmente há cinco ações na justiça questionando o projeto Novo Recife: uma do Ministério Público Federal (MPF), uma do Ministério Público estadual de Pernambuco (MPPE) e três ações populares. Estas ações, de modo geral, argumentam que os prédios irão bloquear a paisagem da cidade. Somado a uma série de outros problemas, como o desconhecimento dos impactos socioambientais da obra e a não abertura de canais de comunicação com a população local, este projeto gerou um clima de insatisfação entre alguns moradores da cidade que, no dia 23 de maio de 2012, na primeira audiência pública sobre o projeto Novo Recife, criaram o grupo DU (Direitos Urbanos). O grupo então exigiu estudos que apontariam os pontos positivos e negativos do projeto, como estudos de impacto ambiental e estudos do impacto que o empreendimento gera ao seu entorno, em razão de seu porte e das atividades que serão exercidas no local. No entanto, no fim de 2012, o projeto foi aprovado na Prefeitura do Recife pela CDU (Barbosa, 2014).

Na madrugada do dia 21 de maio de 2014 o Consórcio Novo Recife conseguiu autorização da prefeitura para demolir os armazéns de açúcar abandonados do Cais José Estelita. Na 
mesma noite os moradores da cidade ocuparam a área referente ao empreendimento questionado na tentativa de impedir a demolição. O que seria apenas uma manifestação contra a demolição dos armazéns, acabou se tornando o que ficou conhecido como "Ocupe Estelita", vários manifestantes ocupando diariamente o local, para impedir que uma nova demolição fosse iniciada (Truffi, 2014).

Na manhã do dia 22, a demolição foi embargada por uma medida judicial provisória do Instituto do Patrimônio Histórico e Artístico Nacional (IPHAN), sob a alegação de que o consórcio descumpriu um termo de ajuste de conduta entre o consórcio e o IPHAN, que visava garantir a proteção dos registros relacionados à produção de conhecimento sobre a área. No dia 3 de junho de 2014, a prefeitura suspendeu a licença que autorizava a demolição dos galpões do Cais. Dois dias depois o Consórcio Novo Recife anunciou que estava aberto para discussão e criação de um novo projeto para a região (Prefeitura do Recife, 2014).

Já no dia 16 de Junho do mesmo ano, o Conselho de Arquitetura e Urbanismo de Pernambuco (CAU) se reuniu com o Conselho Regional de Engenharia e Agronomia (CREA), o Instituto de Arquitetos do Brasil (IAB) e a Universidade Federal de Pernambuco e estabeleceram um prazo de 30 dias para que fossem modificadas as diretrizes urbanísticas do projeto Novo Recife (Prefeitura do Recife, 2014).

O empreendimento proposto pelo consórcio "Novo Recife" está rodeado de discussões polêmicas acerca de sua legalidade e impacto na região central do Recife. Diante disso, consideramos que a questão se mostra um tema atual e oportuno para discutirmos as emergentes políticas habitacionais e de revitalizações dos centros em cidades periféricas e o papel desempenhado pelas parcerias público-privadas nesse processo .

Partindo de uma concepção de que a verdade é produto de condições históricas e contingenciais, e utilizando-se do método arqueológico de Michel Foucault, questionamos nesta pesquisa qual o discurso do "Novo Recife", quais formações discursivas o constitui e sobre qual base este discurso é possível. O agente discursivo analisado aqui é a Prefeitura Municipal do Recife, particularmente sua articulação com o Consórcio "Novo Recife". 


\section{Referencial teórico}

\subsection{O planejamento estratégico na gestão pública}

As cidades expressam variadas formas e dimensões de organização social. Nas sociedades capitalistas, as cidades são os lugares de comando desse sistema, o lugar de produção e reprodução do sistema capitalista. Esse sistema só é possível por causa das cidades. Segundo Oliveira e Barreira (2011, p.1), "elas são os nós da rede produtiva contemporânea, donas de uma estrutura de transmissão de informações e produção de conhecimentos jamais tidos na história da humanidade".

Ao longo da história, as cidades se constituíram como espaços de hegemonia religiosa e política, mas, principalmente depois do advento da Revolução Industrial, passaram a ser um espaço essencial para a existência do sistema capitalista e assumiram de vez o lugar do mercado. No decorrer dos anos, o setor privado foi exercendo, gradativamente, ainda mais influência na governança das cidades. No Brasil, esta influência cresceu em importância, a partir dos anos noventa sob o teto do neoliberalismo, que prescreve a participação do setor privado como requisito para uma boa gestão pública. Esta ideia está imbricada na maioria dos modelos de empreendedorismo urbano das cidades brasileiras que passam a ser protagonistas de experiências centradas na junção entre público e privado na gestão de seus territórios (Leal, 2012).

As práticas de gestão pública, introduzidas no Brasil no final dos anos noventa, se pautaram por princípios de governança expressos na visão das cidades como lócus de empresarialismo urbano (Harvey, 1996, p. 50). Segundo Castells e Borja (1996), esta visão acredita que as cidades são instrumentos eficazes para dar respostas às crises e para atender às aspirações de sua inserção econômica no contexto global, tornando-as palco para a emergência de novas expressões de lideranças e de gerência administrativa.

Não estamos pretendendo dizer que o domínio econômico na governança pública é uma novidade na administração pública brasileira e começou nos anos noventa. Pelo contrário, sabemos que a penetração dos interesses privados (empreiteiras, bancos, imobiliárias, etc.) e a representação de seus agentes nos espaços públicos não se constituem como um fato novo na cultura política do Estado Brasileiro. As elites tradicionais sempre influenciaram nos assuntos administrativos e sempre exerceram cargos públicos nas três esferas 
governamentais. O que mudou a partir da abertura dos mercados nos anos 1990, com os avanços tecnológicos e a reestruturação produtiva foi a inclusão de outras formas de articulação entre Estado e mercado. "Alianças que iriam favorecer, mais ainda, o poder de pressão dos grupos hegemônicos" (Leal, 2012, p. 64).

Como dito antes, a tradicional forma administrativa modernista-funcionalista de planejamento, dominante até a década de 1970, começou a ser desmontada pela ideologia neoliberal. Neste novo contexto, emerge o chamado "planejamento estratégico", cuja crítica fundamental foi construída no Brasil por autores como Carlos Vainer (2000).

A nova gestão estratégica pressupõe não apenas a presença de um governo local, mas uma coalizão de forças globais e locais denominada de governança urbana, que, segundo Mascarenhas (2014), tem como premissa a atuação conjunta do governo local, da iniciativa privada e da sociedade civil. A premissa implícita deste discurso, segundo Souza (2006, p.129), é a de que: "o que é bom para as empresas e faz a prosperidade econômica aumentar também acaba sendo bom para a população em geral". Dessa forma, o papel do Estado é de pactuar e construir acordos e negócios que permitam a promoção da imagem da cidade.

$\mathrm{Na}$ contramão do tradicional planejamento físico-territorial, o novo modelo de planejamento passa a enfatizar a implementação dos chamados grandes projetos de desenvolvimento urbano como vetores privilegiados e "estruturantes" do desenvolvimento. O processo de destruição-reconstrução da cidade afirma-se por meio do chamado Planejamento Urbano Estratégico, considerado por muitos agentes da questão urbana como a principal (ou melhor, a única) possibilidade de superação do quadro de crise de acumulação materializado na paisagem urbana atual. Os Planos Diretores Municipais (Lei Federal no 10.257/2001), obrigatórios para cidades brasileiras com mais de vinte mil habitantes, muitas vezes têm sido elaborados por alguns gestores públicos como instrumentos legitimadores da implementação desse modelo chamado estratégico na escala dos municípios.

Operações emblemáticas, voltadas para construções monumentais e espetaculares e para a projeção da imagem urbana, tais iniciativas vêm, quase sempre, acompanhadas das parcerias público-privadas, da concessão de vantagens fiscais e da privatização dos espaços 
urbanos (Mascarenhas, 2014). Os grandes projetos de desenvolvimento urbano sintetizam as novas formas de fazer e refazer as cidades do capitalismo contemporâneo. A lógica do mercado, nesse contexto, é alimentada pelas agências multilaterais e pelos consultores internacionais, e passa a dominar o debate, o discurso e a prática das administrações urbanas.

\subsection{Grandes Projetos Urbanos (GPUs) como ferramenta da Gestão Pública}

Conceitualmente, Grandes Projetos Urbanos (GPUs) são iniciativas de renovação urbana, concentradas em determinados setores da cidade, que envolvem agentes públicos e privados, e investimentos que seguem diretrizes de um plano urbanístico apoiado no redesenho do espaço urbano (Someck e Campos Neto, 2005). Altshuler e Luberoff (2003) caracterizam GPUs como intervenções de considerável desembolso de recursos públicos, em parceria com o setor privado, alterando tecidos urbanos para atendimento de novas demandas por transporte individual, relacionado com a era do automóvel. O tema dos GPUs é recente, mas já podemos identificar duas correntes principais que discutem os GPUs.

A primeira, ressalta a inserção dos GPUs em um processo amplo de planejamento estratégico, supostamente participativo. Entende que através de um planejamento estratégico entre poder público (viabilizadores), poder privado (investidores) e comunidades (usuários) é possível maximizar e compatibilizar os esforços e investimentos, e implementar ações integradas de curto, médio e longo prazos. Por outro lado, a segunda corrente, contesta a própria possibilidade de um consenso democrático em torno de grandes projetos e adverte sobre os riscos envolvidos com a implementação de GPUs. Nessa linha de pensamento, Harvey (2000) aponta que, para a viabilização dos GPUs, o poder público assume os riscos, enquanto o setor privado assume os lucros resultantes dessas intervenções. Os resultados positivos, por sua vez, fazem atrair novos investidores, novos moradores e novos consumidores, e geram novos projetos (Del Rio, 2000).

No caso da Região Metropolitana de Recife, são exemplos de grandes projetos em andamento o bairro planejado Reserva do Paiva, a Cidade da Copa, em São Lourenço da Mata e na região central, a Via Mangue; e estão em implementação e tramitação legal os projetos Novo Recife, Vila Naval e Parque Capibaribe. 
O projeto Novo Recife gira em torno de dois principais temas: a mobilidade e a revitalização de áreas centrais. Algumas zonas são privilegiadas nestes processos de revitalização urbana: centros históricos, áreas centrais degradadas e vazios urbanos resultantes do processo de desindustrialização - antigas zonas portuárias, ferroviárias e industriais. Na área do Cais José Estelita estão os terrenos antes dedicados ao sistema ferroviário ocupados também por armazéns do Instituto do Açúcar e do Álcool._Na figura 2 podemos comparar a mudança de paisagem que o projeto pode realizar na referida área.

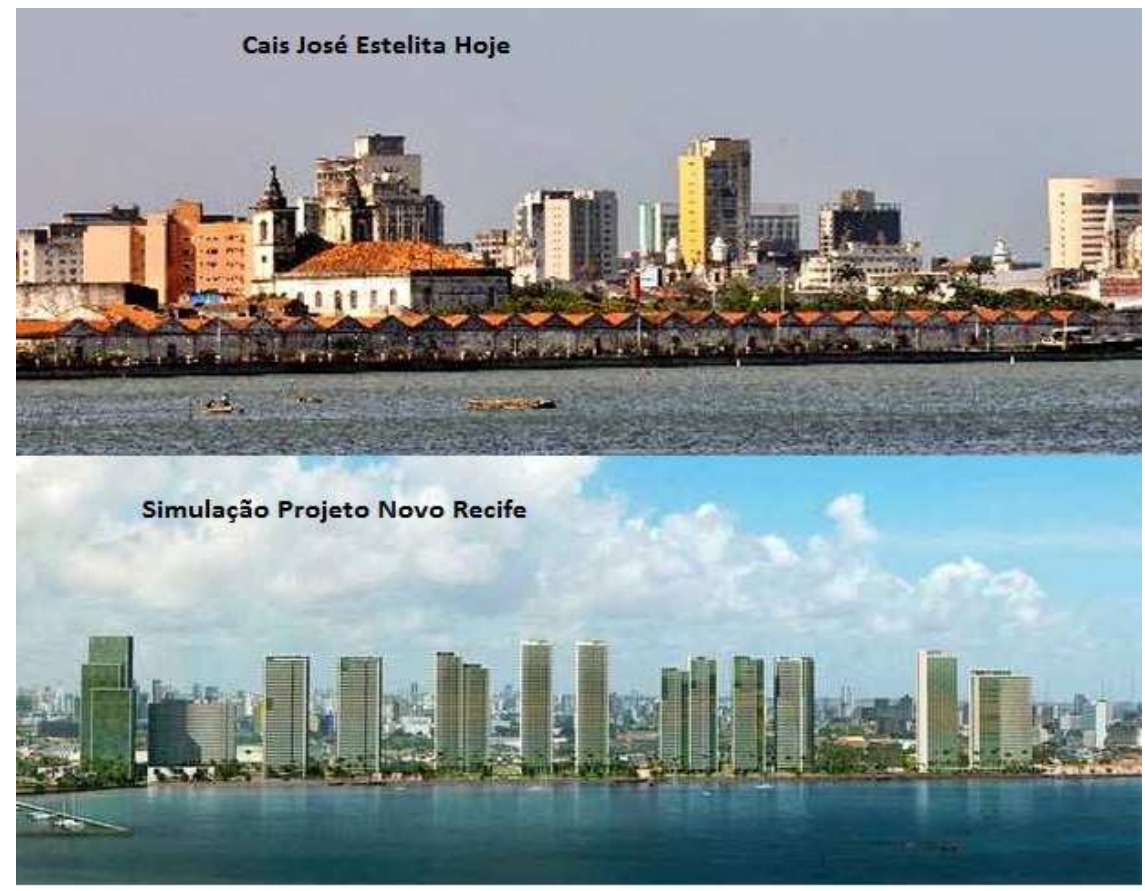

Figura 2: Imagem comparada do Projeto Novo Recife Fonte: Novo Recife, 2011

Como dito na seção anterior, o planejamento urbano foi significado de forma a estabelecer a cidade como base para o crescimento econômico e lugar de fluxo de capital, material, informação e transporte. Aqui se faz presente a lógica econômica. Esta lógica é caracterizada pelo incentivo a redução de custos e ao aumento do retorno econômico e financeiro das cidades. Faz com que prefeitos e planejadores urbanos entendam que cada intervenção urbana tenha que gerar retorno financeiro, mostrar-se lucrativa ou não onerosa aos cofres públicos.

Entendemos que a implementação de GPUs é um campo privilegiado de legitimação de projetos políticos ou de projetos de poder: peças do jogo político dos municípios e/ou estados onde são implementados, quase sempre associados à imagem de uma gestão 
específica ou de um grupo político. A regra da agilidade e do aproveitamento de oportunidades tende a isentar os GPUs de formas efetivas de controle social como, por exemplo, votação e acompanhamento dos cidadãos. Consideramos que o discurso da Prefeitura do Recife está alinhado a este modelo de planejamento estratégico e apresenta uma gestão urbana-empresarial voltada para melhorar a eficiência tanto econômica quanto social da cidade. Neste cenário, a cidade se envolve em uma verdadeira "Guerra fiscal" (Santos e Silveira, 2002, p. 112), e os lugares tornam-se obrigados a oferecer todos os tipos de vantagens possíveis para se transformarem em sedes das empresas e de outros tipos de investimentos.

\section{Procedimentos metodológicos}

Nesta seção expomos a base epistemológica e descrevemos o procedimento arqueológico proposto por Michel Foucault e especificamos as táticas adotadas na construção do corpus, coleta e análise de dados.

Ao utilizar o método foucaultiano, este trabalho assume que a realidade é uma construção social e segue a tradição da pesquisa qualitativa (Creswell, 2010; Flick, 2009; Leão et al., 2011; Denzin e Lincoln, 2006), alinhando-se ao paradigma crítico de pesquisa, que não visa, apenas, interpretar, mas questionar os valores e normas sociais (Lincoln e Guba, 2006).

Em A Arqueologia do Saber (1969), Foucault caracteriza método arqueológico como caminho para descobrir e descrever as regras que dirigem os discursos e entender a construção dos objetos desse discurso, ou seja, arqueologia é uma estratégia de análise do discurso. Isto significa segundo Foucault:

[...] que consiste em não mais tratar os discursos como conjuntos de signos (elementos significantes que remetem a conteúdos ou a representações), mas como práticas que formam sistematicamente os objetos de que falam. Certamente os discursos são feitos de signos; mas o que fazem é mais que utilizar esses signos para designar coisas. É esse mais que os torna irredutível à língua e ao ato de fala. É esse "mais" que é preciso fazer aparecer e que é preciso descrever (Foucault, 2008, p. 55).

Foucault, através da investigação arqueológica, constata que em cada época há uma episteme diferente, que torna possível o surgimento de novos saberes (Foucault, 2008). 
Podemos entender episteme como o paradigma que guia o discurso. Este, conceito fundamental no trabalho de Foucault, revela um conhecimento posto e relativo ao tempo ou espaço. Para Foucault (2008, p. 133), discurso é "um conjunto de enunciados, na medida em que se apoiem na mesma formação discursiva".

Outro conceito fica em aberto na definição acima: o enunciado. Podemos inferir que um enunciado é qualquer frase ou proposição. No entanto, não se resume a isto. Enunciados são a unidade mínima de significado do discurso. São unidades do saber que compõem práticas discursivas (Foucault, 2008). Mais precisamente, os enunciados são "uma função que cruza um domínio de estruturas e de unidades possíveis e que faz com que apareçam conteúdos concretos, no tempo e no espaço (Foucault, 2008, p. 98).

Na primeira etapa de análise, além de revelar os enunciados, buscamos evidenciar a função que cada enunciado desempenha no discurso. A Função enunciativa "é uma ação que se revelou na prática enunciativa pela existência de um domínio de saberes a ela associados" (Costa e Leão, 2011, p. 307). Dessa forma, assim como especifica Foucault (2008), a função enunciativa faz aparecer o enunciado como um objeto específico capaz de agir, de diversas formas, no discurso.

O Segundo nível de análise exigiu maior reflexão, pois nesta etapa saímos do nível empírico para um esforço mais conceitual: a categorização das regras do discurso. Para Foucault, a regra é uma prática social que gera sentido aos signos. O mesmo apresenta quatro categorias de regras que podemos identificar no discurso: objetos, conceitos, modalidade de enunciação e estratégias. Os primeiros derivam do discurso e são definidos por relações entre conceitos. Os segundos são elementos discursivos decorrentes que estão presentes nos enunciados. O terceiro é a forma como o discurso é praticado; procura identificar quem fala, onde se fala e qual a posição que ele se coloca; tenta encontrar o sujeito falante, o local onde está inserido e a posição dele. A quarta e última categoria é a estratégia, pode ser entendida como uma certa razão de ser do discurso, as estratégias mostram que existe uma intencionalidade na prática discursiva (Foucault, 2008). São estes elementos que permitem compreender a regularidade do discurso. Essas categorias são reguladas em seu aparecimento e transformação por regras que as constituem. 
Na proposta de Foucault, os quatro níveis de análise que constituem as regras não são elementos dados, mas condições de possibilidade que tornam possível seu aparecimento e transformação. São estas regras que caracterizam o discurso como regularidade e delimitam as chamadas Formações Discursivas (Foucault, 2008).

Assim, ter o discurso como objeto de estudo é estabelecer sua regularidade. "São as relações entre objetos, entre tipos enunciativos, entre conceitos e entre estratégias que possibilitam a passagem da dispersão à regularidade" (Machado, 2006, p. 165). Segundo Giacomoni e Vargas (2010, p.5), o que Foucault faz na Arqueologia do Saber, ao descrever a formação discursiva, nada mais é do que definir "aquilo que é essencial para compreender a constituição de um saber".

Neste ponto, chegamos ao último nível de análise: o de demonstração das Formações discursivas caracterizadas no discurso. A formação discursiva é uma unidade macro que guarda em si possibilidade de verdade. Foucault (2008, p. 43) define como:

No caso em que se puder descrever, entre um certo número de enunciados, semelhante sistema de dispersão, e no caso em que entre os objetos, os tipos de enunciação, os conceitos, as escolhas temáticas, se puder definir uma regularidade (uma ordem, correlações, posições e funcionamentos, transformações), diremos, por convenção, que se trata de uma formação discursiva.

A proposta de Foucault vai na direção de buscar as regularidades que existem por trás da dispersão de elementos do discurso. O autor deixa claro que uma formação discursiva é identificada quando se pode definir o sistema de estratégias que nela se desenrola, ou seja, demonstrar como ela deriva do jogo de relações inerentes ao discurso (Foucault, 2008).

\subsection{Construção do arquivo}

Para Foucault, arquivo são todos documentos a serem selecionados e analisados. Devem conter os discursos a serem investigados sobre uma certa ordem discursiva em um dado momento histórico (Foucault, 2008). Podemos considerar, salvo algumas especificidades, o que Foucault chama de arquivo é o mesmo que o conceito de corpus que utilizamos em pesquisa qualitativa (Creswell, 2010).

O corpus deste trabalho foi composto por documentos dos dois sujeitos políticos analisados, a Prefeitura do Recife e o Consórcio de empresas denominado "Novo Recife". Os 
documentos selecionados representam fontes importantes para entender a posição discursiva desses dois sujeitos políticos sobre o Projeto Novo Recife. O corpus foi formado pelo Relatório de empreendimento de impacto: Empreendimento Novo Recife (Proposta do projeto elaborado pelo consórcio em 2011); Parecer aos Projetos de Construção para Uso Misto (parecer urbanístico realizado em 2015 pela Diretoria de Urbanismo da Secretaria de Controle, Desenvolvimento Urbano e Obras da Prefeitura do Recife aprovando o início da construção do projeto) e Notas especiais da Prefeitura do Recife sobre o Projeto Novo Recife, coletadas no site oficial da Prefeitura e no Diário Oficial de Pernambuco, emitidos no período entre 2012 e 2016.

O processo analítico arqueológico deste trabalho foi inspirado nos procedimentos elaborados por Costa e Leão (2011) e Camargo e Leão (2013). A análise se deu em três etapas: primeiro buscamos identificar os enunciados e suas relações com as funções enunciativas, posteriormente, identificamos as regras e suas categorias para, enfim, desvelar as formações discursivas.

Os dados e análise dessa pesquisa suscitaram reflexões que aprofundam a compreensão do fenômeno estudado. No entanto, o estudo em questão apresentou algumas limitações de tamanho de corpus e de proposta analítica. A proposta de arqueologia foucaltiana pode não atingir a profundidade necessária para entender as subjetividades de um discurso necessitando de uma segunda fase de análise que Foucault (2008) denomina de genealogia, ou seja, ir à gênesis do discurso. Em pesquisas posteriores essas limitações podem ser sanadas.

\section{Descrição dos resultados}

\subsection{Enunciados}

Numa leitura inicial tentou-se destacar os temas principais tratados nos documentos. As unidades discursivas do arquivo (corpus) são os enunciados. Eles constroem o discurso, portanto, desvelam saberes. Cada enunciado provém de uma multiplicidade, mas como cada um faz emergir um saber (verdade) específico, foram transcritos como proposições 
afirmativas. Numa leitura mais profunda foram encontrados nove enunciados, através da observação e destaque de frases, expressões, palavras, argumentos e algumas ideias distribuídas ao longo do texto. Estes enunciados fazem parte das práticas discursivas dos agentes do discurso analisados aqui: a Prefeitura Municipal do Recife e Consórcio Novo Recife.

Como forma de exemplificar a construção dos enunciados, deixando claro que os enunciados não foram produzidos, apenas, com as expressões citadas, segue recorte do texto que ajuda no entendimento da construção dos enunciados propostos:

A área do Cais José Estelita está abandonada e sem uso já há alguns anos, constituindo um vazio urbano bastante prejudicial à ambiência urbana e à dinâmica econômica da cidade. A ocupação deste vazio urbano será determinante para o início de um novo ciclo de desenvolvimento da área composta pelos Bairros de São José, Cabanga e aos eixos viários Avenida Sul e Rua Imperial e suas edificações (Memorial Novo Recife, 2011, p. 2)

Este recorte possibilitou construir o enunciado "O Cais José Estelita impede o desenvolvimento da cidade". É claro no texto que o Cais José Estelita impossibilita que a cidade se desenvolva, o que exige a ocupação deste espaço para iniciar um novo ciclo de desenvolvimento da área. O mesmo recorte ajudou a construir o enunciado "O 'Novo Recife' é fundamental para o desenvolvimento econômico da cidade", no momento em que deixa claro a necessidade de ocupação do espaço para facilitar a dinâmica econômica da cidade. Além do trecho citado, este último enunciado foi construído levando em consideração outros recortes do texto, como o que segue:

A viabilidade construtiva de um empreendimento é resultante de estudos de viabilidade econômica realizados pelo grupo empreendedor a partir das interferências sofridas pela região, entre elas a legislação municipal vigente (Memorial Novo Recife, 2011, p. 6).

Estes e os demais enunciados foram construídos seguindo os critérios de regularidade e repetição de significados que aparecem no discurso e, ao mesmo tempo, apontam para diferenças que demarcam a unidade de cada enunciado (Costa e Leão, 2011). Para facilitar o entendimento e visualização, os enunciados serão apresentados seguidos de sua descrição.

\section{O Cais José Estelita impede o desenvolvimento da cidade}

Este enunciado diz que a região do cais tem potencial de desenvolvimento. Porém, no momento encontra-se num estado que dificulta a vigilância, a mobilidade, integração e a 
dinâmica da cidade. Por isto, o enunciado pronuncia que a região é isolada, uma ilha urbana, que impede que o centro se desenvolva.

\section{O Novo Recife é o melhor para qualidade de vida da população}

Este enunciado se manifesta de várias maneiras, as vezes, argumentando que o empreendimento assegura a dinâmica social e requalifica a região, outras vezes, que valoriza os espaços públicos para oferecer oportunidades de lazer e recreação para os citadinos. As vantagens oferecidas pelo empreendimento são em muitas passagens vinculadas aos conceitos de qualidade de vida e bem-estar social, considerados como parte importante para os citadinos.

\section{O “Novo Recife" é fundamental para o desenvolvimento econômico da cidade}

Apesar de outros enunciados também abordarem o desenvolvimento da região e vinculá-lo à melhora da economia, este enunciado se diferencia dos demais por demonstrar a importância do empreendimento para o crescimento econômico da cidade como fator primordial da construção do projeto. No desenho do projeto, além dos edifícios para habitação, inclui-se dois edifícios empresariais e um hotel. O enunciado pronuncia que o Novo Recife facilita a integração de Recife na economia, melhora o turismo no centro da cidade e permite tornar a região um centro econômico. Justifica-se o Novo Recife, principalmente, por proporcionar crescimento econômico.

\section{O Novo Recife está alinhado com o planejamento urbano da cidade}

O enunciado pronuncia que o empreendimento está de acordo com o planejamento do município. Faz parte do planejamento para o aumento de empreendimentos urbanísticos da Região Metropolitana do Recife e segue a legislação municipal vigente. Por tanto, o Novo Recife é fruto do bom planejamento urbano da Prefeitura do Recife.

\section{O Novo Recife está de acordo com o modelo de urbanização mundial}

O enunciado pronuncia que o empreendimento está de acordo com um urbanismo contemporâneo. É igualado aos grandes empreendimentos ao redor do mundo. Este fato é demarcado no texto como sinal de um bom caminho para urbanização da cidade. É apresentado com certa satisfação no discurso. Faz parte do tipo de urbanização das grandes cidades mundiais, marcados por edifícios de muitos andares, condomínios fechados, 
enormes espaços privados para convívio social e consumo, como shoppings centers, e valorização do carro como meio principal de locomoção. O projeto cria nova visão ao urbano da cidade, considerado desatualizado, possibilita um novo urbanismo para o centro da Cidade. Por isso é tratado como referência.

\section{O Novo Recife é produto da vontade do povo}

É recorrente a demonstração de que o empreendimento passou pela aprovação de várias instâncias municipais e da sociedade civil. O projeto foi discutido pelas organizações da sociedade civil envolvidas. A maioria dos membros da comissão de controle urbanístico aprova o projeto. Em diversas passagens e maneiras este enunciado é apresentado no texto. O projeto é resultado de acordos com a sociedade, a população pede requalificação da área, através de um projeto como o Novo Recife.

\section{O Novo Recife contribui para uma cidade Sustentável}

O enunciado articula que o projeto segue todas as exigências ambientais estabelecidas por lei. É entendido como fundamental para o desenvolvimento sustentável da cidade. Ao demonstrar as qualidades do projeto (grandes espaços entre cada edifício para possibilitar a circulação do ar, vários espaços públicos arborizados, praças de convivência, biblioteca pública, ruas alargadas para pedestres e ciclistas, dois edifícios garagem facilitar a mobilidade, etc.), as consideram característica de uma cidade sustentável. Assim sendo, o Novo Recife auxilia na construção de uma cidade mais sustentável.

\section{O Novo Recife respeita o patrimônio cultural da cidade}

Este enunciado profere que o Novo Recife considerou as questões de preservação do patrimônio histórico do centro do Recife. Grande parte da área do projeto não foi considerada como valor cultural para a sociedade. O consórcio argumenta que o empreendimento não tem impacto visual na área histórica da região já que as 12 torres serão construídas onde hoje são localizados os antigos galpões no Cais José Estelita. Estes galpões, e a área onde estão localizados, não apresentam valor cultural para cidade, segundo o Instituto do Patrimônio Histórico e Artístico Nacional.

\section{O Novo Recife causa danos que serão mitigados}


A prefeitura se preocupa com os possíveis danos do projeto e trabalha para que isso não aconteça. O Novo Recife é o projeto com maior número de ações mitigadoras no histórico dos empreendimentos urbanísticos do Recife. Foi determinado ao consórcio a construção de ciclovias, praças, mercado popular, entre outras ações que garantam espaços públicos de qualidade. No entanto, muitas vezes, os danos são vistos como possibilidades futuras e não são especificados de forma clara pelo agente do discurso.

\subsection{Funções enunciativas}

As funções enunciativas são reveladas por meio das práticas discursivas, são as ações exercidas pelos enunciados (Foucault, 2009; Costa e Leão, 2011). Como categorias analíticas, as funções serão apresentadas em frases curtas que representem uma ação. As funções enunciativas demarcam o desempenho dos enunciados na instância do campo discursivo, ou ainda, no jogo de relações da formação ao qual fazem parte. Por serem ações dos enunciados, as descrevemos como orações que iniciam sempre com um verbo no infinitivo. Nesta análise, as funções enunciativas foram refletidas com base em como os enunciados foram utilizados no discurso, identificando as ações. Como exemplo ilustrativo, podemos explicar a construção da função "Convencer que o Novo Recife é o que a cidade precisa e deseja", através do recorte que segue:

É verdade que existiram outros desenhos urbanos para a ocupação da área, mas, este foi o resultado que, na visão da equipe, melhor contribuirá para promover a integração social, o respeito ao patrimônio e a inclusão social, partindo do princípio que a abordagem que traz maiores benefícios para todos é um meio-termo que permita a viabilização do empreendimento e reflorescimento da comunidade (Prefeitura do Recife, 2015, p. 7).

Ao apresentar a existência de outros desenhos e a escolha do "Novo Recife" como escolha mais adequada entre eles, o agente desempenha a função de convencer que o empreendimento é a melhor opção para a Cidade por abarcar tanto a viabilização (econômica) quanto à integração social. Foram identificadas um total de seis funções que estão citadas e descritas no Quadro 1. 


\begin{tabular}{|l|l|}
\hline \multicolumn{1}{|c|}{ Funções Enunciativas } & \multicolumn{1}{|c|}{ Descrição } \\
\hline Desqualificar Cais José Estelita & $\begin{array}{l}\text { Desempenha a ação de demonstrar que o Cais José Estelita é } \\
\text { um problema para região do centro da cidade, } \\
\text { desqualificando-o }\end{array}$ \\
\hline $\begin{array}{l}\text { Defender o "Novo Recife" como } \\
\text { fundamental para a economia }\end{array}$ & $\begin{array}{l}\text { Desempenha a função de defender que o projeto irá induzir } \\
\text { crescimento econômico na região, através do estabelecimento } \\
\text { de empresas, comercio popular, consumo e integração com as } \\
\text { outras regiões da cidade }\end{array}$ \\
\hline $\begin{array}{l}\text { Promover o Novo Recife como referência } \\
\text { de urbanismo contemporâneo }\end{array}$ & $\begin{array}{l}\text { Desempenha a função de promover o Novo Recife como } \\
\text { referência de planejamento urbano moderno e planejado, } \\
\text { desenvolvido nas grandes cidades mundiais, para que a Cidade } \\
\text { do Recife seja considerada desenvolvida }\end{array}$ \\
\hline $\begin{array}{l}\text { Convencer que o Novo Recife é o que a a } \\
\text { cidade precisa e deseja }\end{array}$ & $\begin{array}{l}\text { Desempenha a função de persuadir a população para perceber } \\
\text { o Novo Recife como a melhor opção ambiental e } \\
\text { socioeconômica para o Centro do Recife. Que reflete a vontade } \\
\text { e o desejo dos citadinos, na medida em que foi discutido e } \\
\text { aceito pelos representantes de várias instâncias sociais }\end{array}$ \\
\hline $\begin{array}{l}\text { Demonstrar que o "Novo Recife" respeita } \\
\text { a história e o ambiente da cidade }\end{array}$ & $\begin{array}{l}\text { Desempenha a função de evidenciar que o Novo Recife cumpre } \\
\text { com as determinações ambientais e não fere o meio ambiente } \\
\text { e o patrimônio histórico da cidade }\end{array}$ \\
\hline $\begin{array}{l}\text { Convencer que os danos do projeto serão } \\
\text { mínimos }\end{array}$ & $\begin{array}{l}\text { Desempenha a função de convencer que o projeto não terá } \\
\text { grandes danos e os que existem ou existirão serão mitigados } \\
\text { pelo consórcio }\end{array}$ \\
\hline
\end{tabular}

Quadro 1: Funções Enunciativas

Fonte: elaborada pelos autores, 2017

As ações mais exercidas no discurso foram as de "Demonstrar que o "Novo Recife" respeita a história e o ambiente da cidade" e "Convencer que os danos do projeto serão mínimos". Vários enunciados convergem para estas duas funções. Isto demonstra a preocupação do sujeito em convencer que o "Novo Recife" não ocasionará danos graves à população, à identidade visual e histórica, e ao meio ambiente.

As seis funções encunciativas encontradas nos discursos analisados podem ser enquadradas em duas ações principais: a de demonstrar que o Cais José Estelita é um problema para o Recife; e a de convencer/promover o Projeto Novo Recife como a melhor solução para este problema. O trecho que segue apresenta a preocupação do empreendimentno em deixar claro seus impactos positivos na área:

O Empreendimento NOVO RECIFE se apresenta, pela localização, dimensão e programa de usos como uma proposta impactante para a vizinhança, a região e a cidade do Recife. Neste aspecto, como agente indutor de impactos positivos, na forma demonstrada pelo presente MEMORIAL JUSTIFICATIVO. A leitura das informações contidas nos quatro componentes que estruturam o Memorial, a saber: ambiente natural, ambiente construído, infraestrutura e mobilidade, permite afirmar quanto ao acerto do Empreendimento, e seus benefícios para a cidade (Memorial Novo Recife, 2011, p. 69). 


\subsection{Regras do discurso}

As regras definem as condições de existência do enunciado (Foucault, 2009). É uma prática social (Foucault, 2009) aqui mediada pelos documentos oficiais dos sujeitos analisados. As regras construídas partem de um nível conceitual baseado nos dados empíricos. Foram identificadas três regras que norteiam esta prática social.

Além das relações estabelecidas entre enunciados e funções, a exemplo de como as regras foram identificadas seguem recortes no qual a regra "O Novo Recife é sustentável" é identificada em meio aos argumentos que justificam o empreendimento como sustentável:

Buscou-se construir uma solução que possa agregar mais valor ambiental, econômico, social e espacial para a cidade sem esquecer os aspectos intangíveis, como o fortalecimento da comunidade local e o conforto dos usuários.

A prefeitura entende que é justamente uma solução de ocupação da área que pode fomentar desenvolvimento da dinâmica urbana e econômica desta região da cidade, portanto, viabilizar empreendimentos nesta área, buscando caminhos sustentáveis, é o primeiro passo a ser dado para promover o seu desenvolvimento.

A regra "O Novo Recife é sustentável" deixa claro que o projeto é guiado por uma preocupação com a sustentabilidade social e ambiental, por isso, demonstra está de acordo com as obrigações ambientais, as entidades da sociedade civil estão envolvidas no projeto, respeita o patrimônio histórico da cidade e preza pela melhoria da qualidade de vida população. Esta sustentabilidade está baseada no tripé: social, ambiental e econômico. No entanto, muitas vezes, o agente discursivo justifica a capacidade de ser sustentável através do crescimento econômico. Este é entendido aqui como condição necessária para.

A regra "Grandes empreendimentos como solução dos problemas urbanos", por sua vez, permite entender que o Novo Recife é estabelecido numa perspectiva em que os grandes empreendimentos são tratados como solucionadores dos problemas urbanos. Capazes de requalificar áreas abandonadas e melhorar a dinâmica da cidade. Com projetos que visam grandes áreas são considerados ideais porque proporcionam uma mudança mais rápida e 
notável no espaço, com consequentes mudanças na qualidade de vida da população. Além disso, grandes projetos beneficiam a tríade: sociedade, Estado e empresas.

A regra "O Novo Recife como indutor de crescimento econômico" procura promover, persuadir e justificar que o projeto é capaz de melhorar os resultados econômicos do centro da cidade. Ou seja, gerar lucro através das iniciativas decorrentes da construção.

As regras que norteiam este discurso são constituídas por categorias (objeto, conceito, modalidade, estratégia) que ajudam a explicar cada regra. As categorias de cada regra são apresentadas no Quadro 2.

\begin{tabular}{|c|c|c|c|}
\hline Regras & $\begin{array}{c}\text { Grandes } \\
\text { empreendimentos } \\
\text { como solução dos } \\
\text { problemas urbanos }\end{array}$ & $\begin{array}{l}\text { O Novo Recife como } \\
\text { indutor de } \\
\text { crescimento } \\
\text { econômico }\end{array}$ & $\begin{array}{l}\text { O Novo Recife é } \\
\text { sustentável }\end{array}$ \\
\hline Objeto & $\begin{array}{l}\text { Empreendimentos } \\
\text { Imobiliários }\end{array}$ & Novo Recife & Novo Recife \\
\hline Conceito & $\begin{array}{c}\text { Desenvolvimento } \\
\text { Urbano } \\
\text { Sustentabilidade }\end{array}$ & $\begin{array}{c}\text { Crescimento } \\
\text { Econômico } \\
\text { Desenvolvimento } \\
\text { Urbano }\end{array}$ & $\begin{array}{c}\text { Sustentabilidade } \\
\text { Bem-estar social } \\
\text { Desenvolvimento } \\
\text { Urbano }\end{array}$ \\
\hline Modalidade & $\begin{array}{l}\text { Informativa } \\
\text { Persuasiva }\end{array}$ & $\begin{array}{l}\text { Promocional } \\
\text { Persuasiva } \\
\text { Justificativa }\end{array}$ & $\begin{array}{c}\text { Informativa } \\
\text { Persuasiva } \\
\text { Justificativa }\end{array}$ \\
\hline Estratégia & $\begin{array}{l}\text { Demonstrar os } \\
\text { grandes } \\
\text { empreendimentos } \\
\text { como soluções } \\
\text { urbanísticas } \\
\text { Informar as } \\
\text { qualidades do Novo } \\
\text { Recife }\end{array}$ & $\begin{array}{l}\text { Promover o projeto } \\
\text { como impulsionador } \\
\text { da economia } \\
\text { Justificar a } \\
\text { pertinência do } \\
\text { projeto }\end{array}$ & $\begin{array}{l}\text { Informar as qualidades do } \\
\text { Novo Recife } \\
\text { Convencer que o projeto } \\
\text { será bom para a } \\
\text { sustentabilidade da } \\
\text { cidade } \\
\text { Justificar a pertinência do } \\
\text { projeto }\end{array}$ \\
\hline
\end{tabular}

Quadro 2: Categorias das Regras

Fonte: Elaborado pelos autores, 2017

\subsection{Formações discursivas}

Depois de descrever e explicar brevimente os enunciados, funções e regras que constituiem o discurso, nos ocuparemos nesta seção de analisar profundamente as formações discursivas. Os discursos revelam-se, de fato, nesta unidade. As formações discursivas são uma unidade macro que guarda em si a possibilidade de verdade (Camargo e Leão, 2013). Para chegarmos as formações discursivas consideramos as relações entre enunciados, funções e regras. Tentamos identificar grupos de relações que se assemelham e que, ao 
mesmo tempo, se diferenciam de outras. Dessa maneira foram identificadas duas formações: Econômica e Sustentável. Além de uma grande formação que ordena o discurso: Crescimento Econômico gera sustentabilidade.

A formação discursiva Econômica foi evidenciada pela incidência de enunciados e funções convergentes sobre as regras "Grandes empreendimentos como solução dos problemas urbanos" e "O Novo Recife como indutor de crescimento econômico". Estas duas regras, além de demarcar a formação discursiva, nos fornece informações para acreditar que tal formação é um sistema que entende que através da construção de grandes empreendimentos a região se tornará um centro econômico e permitirá a geração de lucro e o crescimento da economia. É um modelo de urbanismo contemporâneo e exemplo de estratégia adequada para resolver os problemas urbanos e sociais da área do Cais José Estelita e de todo centro da cidade e tornar o Recife mais competitivo dentro do "mercado das cidades".

As cidades competem por visibilidade e crescimento de investimentos empresariais, bem como a busca por prêmios. Esta competição gera uma hierarquia que se estabelece em função de centralidades e especializações no espaço de fluxos. A centralidade é definida pela capacidade de controle e direção da produção, do capital e da tecnologia. Elas competem entre si através da extensão em termos econômicos de área de influência, bem como integram-se de forma cooperativa através dos diversos mercados que atuam. Ou seja, o urbanismo baseado nesta lógica visa formar alicerces para o crescimento econômico. Por este motivo, denominamos a formação discursiva, o nome Econômica.

A formação discursiva Sustentável foi evidenciada pelo conjunto de enunciados e funções que convergiram nas regras "Grandes empreendimentos como solução dos problemas urbanos" e "O Novo Recife é sustentável". Ao mesmo tempo que os grandes empreendimentos imobiliários são considerados solução para os problemas urbanos através da revitalização dos espaços públicos e privados capazes de melhorar a dinâmica da economia local, eles permitem a sustentabilidade da cidade também através da melhoria da qualidade de vida da população. Esta melhoria pode estar ligada aos espaços públicos, valorização do patrimônio histórico, condições ambientais e sociais e poder de participação da população nas decisões urbanísticas da cidade. Foram esses elementos do discurso que permitiram inferir que o empreendimento "Novo Recife" é fruto de um conhecimento que 
norteia a preocupação pelas condições ambientais e sociais da cidade, da região ou do planeta, que denominamos aqui de Sustentável.

As duas formações discursivas, à primeira vista, demonstram uma contradição. É conhecida a discussão por cidades mais sustentáveis e a crítica a um modelo de urbanização que privilegia espaços privados, sem vida, que diminui os espaços públicos de convivência em detrimento do aumento de espaços que privilegiam o coletivo e o direito de usufruir da cidade. Esta crítica é baseada no entendimento de que o crescimento econômico não é sinônimo de desenvolvimento urbano, pelo contrário, é considerado prejudicial e responsável pela situação de segregação espacial e pela péssima qualidade de vida na cidade.

No entanto, no aprofundamento das análises das relações entre enunciados, funções e regras, percebeu-se que, no discurso analisado, o crescimento econômico é fator determinante para uma cidade sustentável. Ou seja, sem crescimento econômico não há sustentabilidade. Dessa forma, o agente discursivo entende que não há contradição entre crescimento econômico e sustentabilidade. Esta é consequência daquele. Por isso entendemos que o discurso é organizado por uma formação discursiva mais abrangente, que denominamos de Crescimento Econômico gera Sustentabilidade. A região na qual o projeto Novo Recife será construído é descrita como importante para o contexto econômico, facilitador da integração mundial de mercados, etc. Neste sentido, a região do centro do Recife apresenta vantagens competitivas que a colocam na trilha do desenvolvimento estruturado. Como podemos ver nos trechos que seguem:

"O fenômeno da urbanização em geral, e nos países da América Latina e no Brasil em especial, estabeleceu, nos últimos vinte anos, um novo processo de desenvolvimento (Memorial Novo Recife, 2011, p. 4)

Os novos paradigmas de desenvolvimento mundial mudaram o papel das cidades na economia. Condicionantes geográficos se apresentam como facilitadores que, influindo nos custos de transportes e comunicação, determinam à importância dessas cidades no contexto econômico. A integração mundial, contudo, atribuiu um papel adicional às cidades, o de imprimir maior eficiência a suas atividades econômicas, sujeitas a acirrada competição (Memorial Novo Recife, 2011, p. 6).

Para descrever o potencial sustentável do centro da cidade, o agente discursivo argumenta características restritas às questões econômicas, como vocação e liderança regional para o empreendedorismo, o comércio varejista (retalhista) e atacadista (grossista) em franca 
expansão tendo em vista, a localização estratégica da cidade; a disponibilidade e grandes áreas para se acolher empreendimentos de porte. Fica evidente que, mesmo utilizando-se de considerações como "respeito ao meio ambiente" e "cidade sustentável", por exemplo, os sujeitos do discurso anlisado reduzem desenvolvimento sustentável a desenvolvimento econômico sustentável.

A prefeitura entende que é justamente uma solução de ocupação da área que pode fomentar desenvolvimento da dinâmica urbana e econômica desta região da cidade, portanto, viabilizar empreendimentos nesta área, buscando caminhos sustentáveis, é o primeiro passo a ser dado para promover o seu desenvolvimento. Na figura 3 são demonstradas as relações entre enunciados, funções e regras que constituiram as formações discursivas e regra das regras.

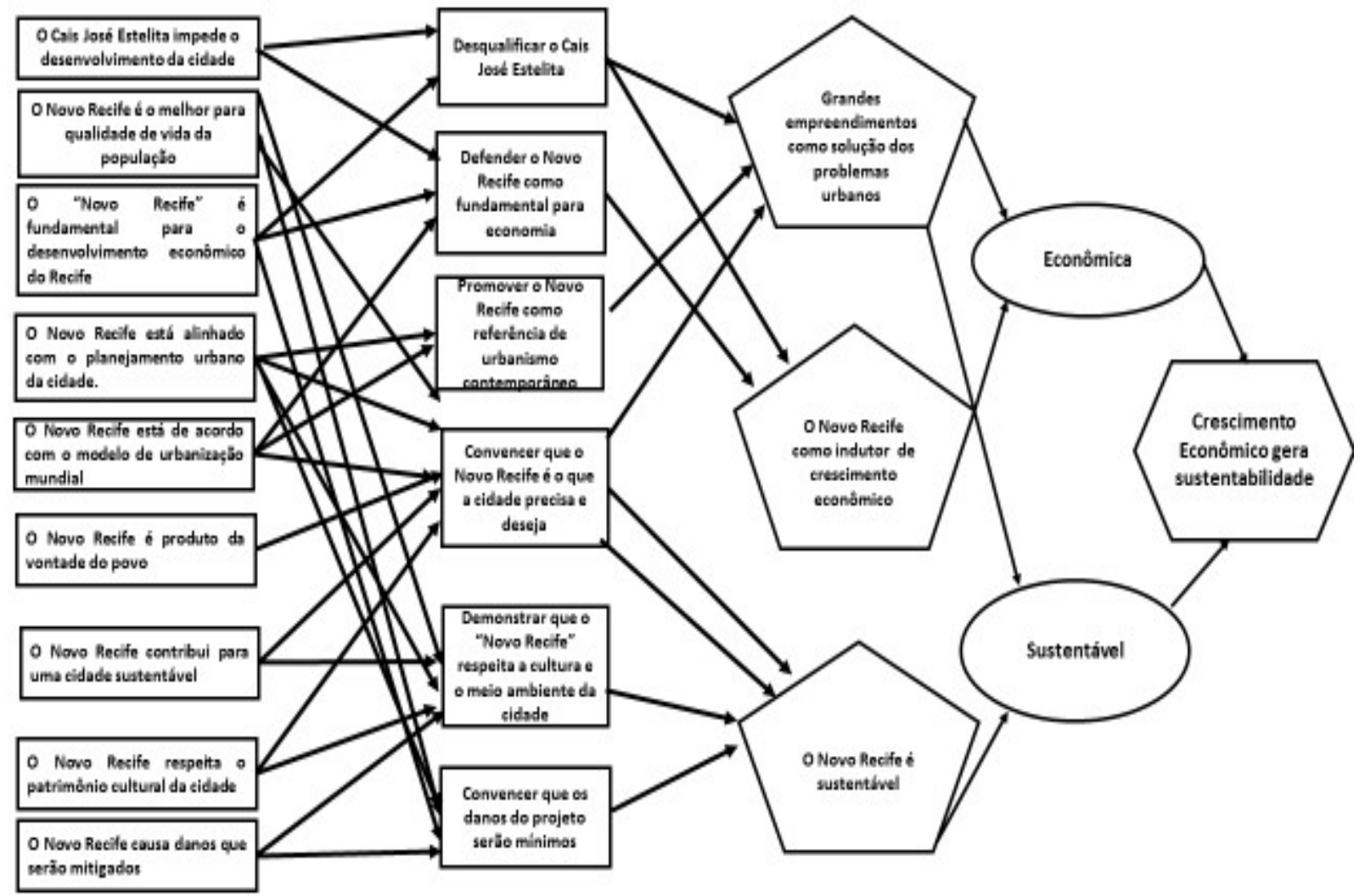

Figura 3: Formações Discursivas

Fonte: Elaborada pelos autores, 2017

Os argumentos propostos pela Prefeitura do Recife evocam, entre outras coisas, a fusão do capital imobiliário (enquanto estratégia) com o Estado, na perspectiva de produzir um espaço, com o intuito de aproveitamento e valorização do solo urbano partindo de uma 
perspectiva de planejamento que utiliza os GPUs como principal ferramenta. Com as análises evidenciamos que o discurso da Prefeitura do Recife tem como paradigma principal uma cidade como base para o crescimento econômico de cunho sustentável.

\section{Considerações finais}

Neste trabalho analisamos através do método arqueológico de Foucault (2008) o discurso do Novo Recife como possibilidade de revitalização do centro da cidade. Sob essa condição desvelamos o conjunto de significados inter-relacionados que nos remeteram ao estabelecimento de uma grande formação discursiva denominada de Crescimento Econômico gera sustentabilidade.

Nas articulações entre enunciados, funções e regras emergiu a condição de que o crescimento econômico é gerador de uma cidade sustentável, através da superconcentração de atividades nas áreas centrais da cidade, construção de grandes empreendimentos imobiliários que impulsionam o crescimento da economia, a geração de emprego e o aumento do lucro de empresas.

A principal tese de Foucault está na ideia de que todo saber (seja científico ou não) só é possível em determinado momento histórico, porque há um espaço de ordem que o possibilita. Partindo da tese foucaultiana podemos entender a contradição da grande regra de formação deste discurso. Entender que o disucurso da Prefeitura do Recife é regulado pela ideia de crescimento econômico como condição de possibilidade de uma cidade mais sustentável e que há uma hegemonia do discurso dos Grandes Projetos Urbanos (GPUs) nas práticas da administração pública. A Regra de formação Grandes empreendimentos como solução dos problemas urbanos demonstrou o uso dessa ferramenta como protagonista das políticas públicas e projetos realizados na cidade do Recife.

Prever o que acontecerá diante dessa articulação foge à finalidade desta pesquisa. É fato, no entanto, que o progresso econômico isolado como fonte de melhor qualidade de vida para a população é uma perspectiva há muito criticada, considerada ultrapassada e, por vezes, nociva à cidade. À raiz disso cabe fazer uma crítica ao modo como os defensores e 
apoiadores do planejamento estratégico se identificam dogmaticamente com as relações capitalistas como a única solução para todas as anomalias e crises da cidade.

Diante do caos urbanístico instalado, o poder público cede ao capital. Desse modo, abre mão da responsabilidade pelo planejamento das cidades e repassa à iniciativa privada que, muitas vezes, tem o lucro como prioridade. Esse tipo Parceria Pública-Privada (PPP) analisada aqui demonstra ser extremamente perigosa, pois pode não representar as vontades e necessidades dos cidadãos. O problema não está no conceito de PPP. As parcerias público-privadas podem ser ferramentas eficientes para uma urbanização de qualidade (MENDONÇA, 2014). Consideramos que o problema esteja no modelo desempenhado por alguns políticos que utilizam os órgãos públicos como moeda de troca para perpetuar-se no poder. O político perde foco e não defende a cidade e seu cidadão. Desenvolver estratégias e soluções que unam crescimento econômico com desenvolvimento sustentável já é um caminho há muito considerado mais viável.

O presente trabalho nos ajuda a discutir os modelos de urbanização vigentes, em especial, nos países periféricos. Especificamente para entender os discursos que surgem de uma nova conjuntura de discussão do urbano na qual o Recife parece fazer parte. Consideramos a metodologia aplicada relevante para o avanço do conhecimento científico por entender que o referencial foucaultiano nos aponta um olhar original para os diversos fenômenos sociais na tentativa de descobrir quais são os problemas específicos que vêm construindo e sustentando o nosso cotidiano.

\section{Referências bibliográficas}

ALTSHULER, Alan; LUBEROFF, David. Mega-Projects: The Changing Politics of Urban Public Investment. Washington, D.C.: Brookings Institution Press, 2003. ISBN 0-8157-0129-2.

BARBOSA, David Tavares. Novos Recifes, velhos negócios: política da paisagem no processo contemporâneo de transformações da Bacia do Pina - Recife/PE: uma análise do Projeto Novo Recife. Dissertação (Mestrado em Geografia) - UFPE. Recife, Pernambuco. 2014.

BRASIL. Lei Federal no 10.257/2001. Estatuto da Cidade. Brasília, DF. 2017.

CAMARGO, Thiago lanatoni. Pulando a cerca ponto com: uma arqueologia do discurso da mercantilização do adultério à luz da estilização da sexualidade de Michel Foucault. Dissertação (Mestrado em Administração) UFPE, Recife, Pernambuco. 2013. 
CASTELLS, M. BORJA, J. As Cidades como atores Políticos. Novos Estudos CEBRAP. 1996, №. 45, julho, pp. 152.. ISSN 0101-3300

COSTA, Flávia Zimmerle da Nóbrega; LEAO, André Luiz Maranhão de Souza. Desvelamento do limiar discursivo de uma marca global em uma cultura local. Cad. EBAPE.BR [online]. 2011, vol.9, n.2, pp.299-332. Disponível em: http://dx.doi.org/10.1590/S1679-39512011000200006. Acedido: 25/abril. 18. ISSN 1679-3951.CRESWELL, John. W. Projeto de pesquisa: métodos qualitativos, quantitativos e mistos. 3a ed., Porto Alegre, Artmed. 2010. ISBN: 9788536323008.

DEL RIO, Vicente. Em busca do tempo perdido. O Renascimento dos centros urbanos. Arquitextos 006, São Paulo, Texto Especial 028, nov. $2000 . \quad$ Disponível em: http://www.vitruvius.com.br/arquitextos/arq000/esp028.asp. Acedido em: 10/abril. 2018. ISSN: 18096298.

DENZIN, Norman K.; LINCOLN, Yvonna. Introdução: a disciplina e a prática da pesquisa qualitativa. In: Denzin, N. K. \& Lincoln, Y. S. O planejamento da pesquisa qualitativa: teorias e abordagens. 2a Ed. Porto Alegre: Artmed. 2006. ISBN: 8536306637

DIÁRIO OFICIAL DO ESTADO. Disponível: <https://www.cepe.com.br/>. Acesso: 01/2016.

FLICK, Uwe. Introdução à pesquisa qualitativa. 3ạ ed. Porto Alegre: Artmed, 2009. ISBN 978-85-363-1711-3.

FOUCAULT, Michel. A Arqueologia do Saber. 7ạ Edição. Rio de Janeiro: Forense Universitária. 2008. ISBN 97885-218-0344-7.

GIACOMONI, Marcello P.; VARGAS, Anderson Z. Foucault, a Arqueologia do Saber e a Formação Discursiva. 2010. Veredas online - análise do discurso - 2/, p. 119-129 - ppg linguística/UFJF - Juiz de Fora - ISSN 19822243.

HARVEY, David. Do gerenciamento ao empresariamento: a transformação da administração urbana no capitalismo tardio. São Paulo, Espaço e Debates. 1996. no 39, p. 48-64. ISSN 0101-5621.

HARVEY, David. Spaces of hope. Berkeley: University of California Press, 2000. ISBN 0.520.22578.3

LEAL, S. M. R. Papel dos atores econômicos na governança das cidades brasileiras. Revista Movimentos Sociais e Dinâmicas Espaciais. 2012. Recife: UFPE/MSEU, v. 01, n. 1, pp. 62-82. ISSN: 22388052.

LEÃO, André Luiz Maranhão de Souza.; MELLO, Sérgio Carvalho Benício de e VIEIRA, Ricardo. O papel da teoria no método de pesquisa em Administração. Organizações em Contexto. 2011. v. 5, n. 10, p. 1-16. ISSN: 19828756.

LINCOLN, Yvonna. S. \& GUBA, Egon. G. Controvérsias paradigmáticas, contradições e confluências emergentes. In: Denzin, N. K. \& Lincoln, Y. S. O planejamento da pesquisa qualitativa: teorias e abordagens. 2a Ed. Porto Alegre: Artmed. 2006. ISBN: 8536306637.

MACHADO, Roberto. Foucault, a Ciência e o Saber. Rio Janeiro: Editora Zahar. 2006. ISBN: 9788571109643.

MARCONDES, Ana Claudia Jorge. Sedimentologia e Morfologia da Bacia do Pina. Dissertação (mestrado) Universidade Federal de Pernambuco. Recife- Pernambuco, 2009.

MASCARENHAS, Gilmar. Cidade mercadoria, cidade-vitrine, cidade turística: a espetacularização do urbano nos megaeventos esportivos. Caderno Virtual de Turismo. Edição especial: Hospitalidade e políticas públicas em turismo. Rio de Janeiro. 2014, v. 14, supl.1, s.52-s.65, nov. ISSN: 16776976.

MENDONÇA, C. Teoria das opções Reais: Aplicação em Parcerias Público- Privadas (PPP), um estudo de caso em sistemas Metroviários. Dissertação (mestrado) - Pontifícia Universidade Católica. Rio de Janeiro-RJ, 2014.

NOVO RECIFE, Consórcio. Relatório de empreendimento de impacto: Empreendimento Novo Recife. Recife: setembro/2011.

OLIVEIRA, Ubiratan Francisco de; BARREIRA, Celene Cunha Monteiro Antunes. Cidades Contemporâneas: "lócus" do capitalismo pós-moderno. Caminhos de Geografia, Uberlândia jun/2011. v. 12, n. 38 p. 75 - 83. ISSN: 1678-6343.

RECIFE. Prefeitura Municipal de Recife. Parecer aos Projetos de Construção para Uso Misto. 2015. Disponível em: $\quad$ http://licenciamento.recife.pe.gov.br/sites/default/files/Paracer\%20relator\%20Novo\%20Recife.pdf. Acedido em: 06 abril. 2016. 
RECIFE. Prefeitura Municipal de Recife. Lei Ordinária 18.138, promulgada em 04 de Maio de 2015. Disponível em: https://leismunicipais.com.br/a1/pe/r/recife/lei-ordinaria/2015/1814/18138/lei-ordinaria-n-18138-2015-. Acedido em: 06 abril. 2016.

SANTOS, Milton; SILVEIRA, Maria Luísa. Uma reorganização produtiva do território. In: Brasil: Território e sociedade no inicio do século XXI. Rio de Janeiro: Editora Record, 2002, p. $105-140$.

SOMECK, Nadia; CAMPOS NETO, Candido Malta. Desenvolvimento local e projetos urbanos. Arquitextos. Texto Especial 059. 2005. Disponível em: http://www.vitruvius.com.br/ revistas/read/arquitextos/05.059/470. . Acedido em: 17 nov. 2017. ISSN: 18096298.

SOUZA, Marcelo. Cidades, globalização e determinismo econômico. Cidades, v. 3, n. 5, 2006b, p. 123-142. ISSN: 24481092.

VAINER, Carlos. B. Pátria, Empresa e Mercadoria: Notas sobre a estratégia discursiva do Planejamento Estratégico Urbano. In: Carlos Vainer; Otilia Arantes; Ermínia Maricato (Org.). A Cidade do Pensamento Único: Desmanchando Consensos. 1a edição. Petrópolis: Vozes. 2000. v. 1, p. 75-104. ISBN 8532623840.

TRUFFI, Renan. A batalha pelo Cais José Estelita. Carta Capital. Jornal Carta Capital. 2014. Disponível em: http://www.cartacapital.com.br/sociedade/a-batalha-pelo-cais-jose-estelita-8652.html. Acedido em: 10 julho. $\underline{2016 .}$ 